Available online at

ScienceDirect

www.sciencedirect.com
Elsevier Masson France

EM|consulte

www.em-consulte.com/en

\title{
e-Health: A promising solution for optimizing management of chronic diseases. Example of the national e-Health project E-care based on an e-platform in the context of chronic heart failure
}

\section{e-Santé : une solution d'avenir pour une prise en charge optimisée des pathologies chroniques. Exemple de la plateforme E-care dans le cadre de l'insuffisance cardiaque}

\author{
E. Andrès ${ }^{a, *}, \mathrm{~S}$. Talha ${ }^{\mathrm{b}}, \mathrm{A}$. Ahmed Benyahia ${ }^{\mathrm{c}}$, \\ O. Keller ${ }^{a}$, M. Hajjam ${ }^{c}$, A. Moukadem ${ }^{d}$, A. Dieterlen ${ }^{d}$, \\ J. Hajjam ${ }^{e}$, S. Ervée, A. Hajjam ${ }^{f}$
}

\footnotetext{
a Service de médecine interne, diabète et maladies métaboliques de la clinique médicale $B$, centre de recherche pédagogique, faculté de médecine de Strasbourg, université de Strasbourg (UdS), CHRU de Strasbourg, 1, porte de l'Hôpital, 67091 Strasbourg cedex, France b Service de physiologie et d'explorations fonctionnelles, faculté de médecine de Strasbourg, université de Strasbourg (UdS), CHRU, Strasbourg, France

c Newel, Mulhouse, France

d Laboratoire MIPS, université Haute-Alsace-de-Mulhouse (UHA), Mulhouse, France

e Centre d'expertise des TIC pour l'autonomie (CenTich) et mutualité française Anjou-Mayenne (MFAM), Angers, France

${ }^{f}$ Laboratoire IRTES-SeT, université de technologie de Belfort-Montbéliard (UTBM), Belfort-Montbéliard, France
}

Received 4 May 2015; accepted 20 August 2015 Available online 26 September 2015

\section{KEYWORDS}

Heart failure;

Telemedicine;

\section{Summary}

Background. - Monitoring patients with heart failure by using telemedicine systems is a potential means for optimizing the management of these patients and to facilitate the job of health

\footnotetext{
* Corresponding author.

E-mail address: emmanuel.andres@chru-strasbourg.fr (E. Andrès).
} 
Detecting signs of cardiac impairment; Follow-up

\section{MOTS CLÉS \\ Insuffisance \\ cardiaque ; \\ Télémédecine ; \\ Détection des signes \\ de décompensation \\ cardiaque ; \\ Suivi}

\section{Introduction}

In France, nearly 1 million people suffer from heart failure (HF), and over 120,000 new cases are diagnosed every year [1-3]. Thereby, HF is a public health problem. Managing HF is a complex, lengthy, often difficult task, with great cost to our society, both in terms of healthcare and treatment time as well as from a financial standpoint $[2,3]$. HF is a chronic disease which, in addition to its significant mortality $(50 \%$ at 5 years for advanced forms), has significant morbidity and induces frequent re-hospitalizations, some of which could be avoided through early action [1]. through the E-care project.

\section{Résumé}

care professionals. We report the experience of the deployment of such a monitoring platform,

Methods. - The national e-heath project $E$-care has developed an "intelligent"' communicative platform enabling the monitoring of patients with NYHA stages III and IV heart failure using noninvasive sensors. This project has been deployed since October 2013 in the Strasbourg University Hospital (in Strasbourg, France).

Results. - To date, more than 180 patients have been included. The patient profile included was: elderly patient, with several chronic diseases $(>90 \%)$, chronic heart failure in more than $60 \%$ of cases, total loss of autonomy in $25 \%$. The $E$-care system operated perfectly and the experimental phase enabled us to validate the technological choices. A qualitative survey helped to positively assess the system's ergonomics. A preliminary analysis of the relevance of alerts with our inference engine design resulted in no malfunction.

Conclusion. - Preliminary results following the deployment of E-care system in hospitals appear to show that this platform will assist health care professionals, especially patient nurse or doctor, by providing an automated processing of these sensors' transmitted data in order to early detect and report signs of cardiac impairment.

(c) 2015 Elsevier Masson SAS. All rights reserved.

Contexte. - Le suivi des patients atteints d'insuffisance cardiaque en utilisant des systèmes élémédecine est un moyen potentiel pour optimiser la prise en charge de ces patients et faciliter le travail des professionnels des soins de santé. Nous rapportons ici l'expérience du déploiement d'un tel système de suivi des patients à travers le projet $E$-care.

Methodes. - Le projet national de télémédecine $E$-care a développé une plate-forme commucante et « intelligente » permettant le suivi des patients insuffisants cardiaques en stades III et IV de la NYHA en utilisant des capteurs non invasifs. Ce projet a été déployé à partir d'octobre 2013 aux hôpitaux universitaires de Strasbourg.

Résultats. - À ce jour, plus de 180 patients ont été inclus. Ces patients sont âgés, polyhologiques dans plus de $90 \%$ des cas, présentant une insuffisance cardiaque dans plus de $60 \%$ des cas, et une perte d'autonomie dans $25 \%$. Cette expérimentation a permis de valider les choix technologiques, les outils et les solutions développées et adoptées pour le suivi des insuffisants cardiaques. Une enquête qualitative réalisée auprès des professionnels de santé a évalué positivement l'ergonomie du système. Une analyse préliminaire de la pertinence des alertes avec le moteur d'inférence n'a pas montré de dysfonctionnement du système.

Conclusion. - Les résultats préliminaires montrent que la plate-forme $E$-care devrait être susceptible d'aider les professionnels de soins de santé, en particulier infirmier, patient ou le médecin, en fournissant un traitement automatisé des données transmises par les capteurs afin de détecter et de signaler de façon précoce des symptômes d'insuffisance cardiaque.

(c) 2015 Elsevier Masson SAS. Tous droits réservés. 
non-invasive sensors. As we describe here, this e-platform is initially deployed and validated in hospital.

\section{Material, patients, methods}

\section{Material}

The E-care project, selected in 2011 as part of the tender: "services numériques pour la santé et l'autonomie"' (Digital services for health and autonomy) (grant: "Investissements d'avenir' 'from the French government), was designed with the principal objective of optimizing patient monitoring, especially by detecting precursor signs of cardiac impairment or acute HF via a telemedicine system [5]. This system is combined with motivational and educational tools. The $E$ care platform enables patients with NYHA Stage III HF to be monitored using non-invasive sensors [5].

The $E$-care platform provides assistance to the health care professionals by automating the processing of data sent from the sensors, automatically generating alerts in order to detect and report risk situations of HF early (Fig. 1) [6,7]. This platform also enables the sharing and management of heterogeneous data so as to integrate the necessary information required for monitoring any underlying pathology, such as diabetes mellitus, renal failure, respiratory insufficiency, and so on.

The early detection of cardiac impairment involves processing data from multiple factors, namely the signal from the electrocardiogram (EKG), heart sounds (phonocardiogram [PCG] signal), weight, blood pressure (BP), oxygen saturation, patient ergonomics, in addition to dietary monitoring, based on the phenotypic data of each patient (personalized medicine) [5-7]. All of these consolidated elements, combined with each patient's individual profile, facilitate not only the detection of cardiac abnormalities, but also the prevention of cardiac impairment risk factors.

The e-platform is built around:

- a console installed in the patient's room, for collecting vital signs;

- non-stationary signal description tools (emitted from the sensors) for the association and synchronization of measurements (e.g. EKG and PCG);

- a central application for the reasoning and processing of physiological and medical data based on semantic web technologies [5-7].

The $E$-care platform uses an ontology designed to define a controlled vocabulary of diseases, medications, symptoms, and so on, as well as to model concepts related to chronic HF monitoring [5-7]. The reasoning portion is based on an inference engine in which the rules are either introduced by medical experts or generated by a data search and subsequently validated by medical experts. The $E$-care system fully capitalizes on its ability to consolidate different data information concerning the patient.

For each patient, E-care processes in real-time the personal data collected by the sensors, then analyzing it in conjunction with the domain ontologies describing their pathologies, medications, and symptoms [5]. This first inference constitutes its first learning process by adding new information to the patient ontology. In the second stage, $E$ care consolidates all the information relative to all patients in order to enhance the system. New rules are then added

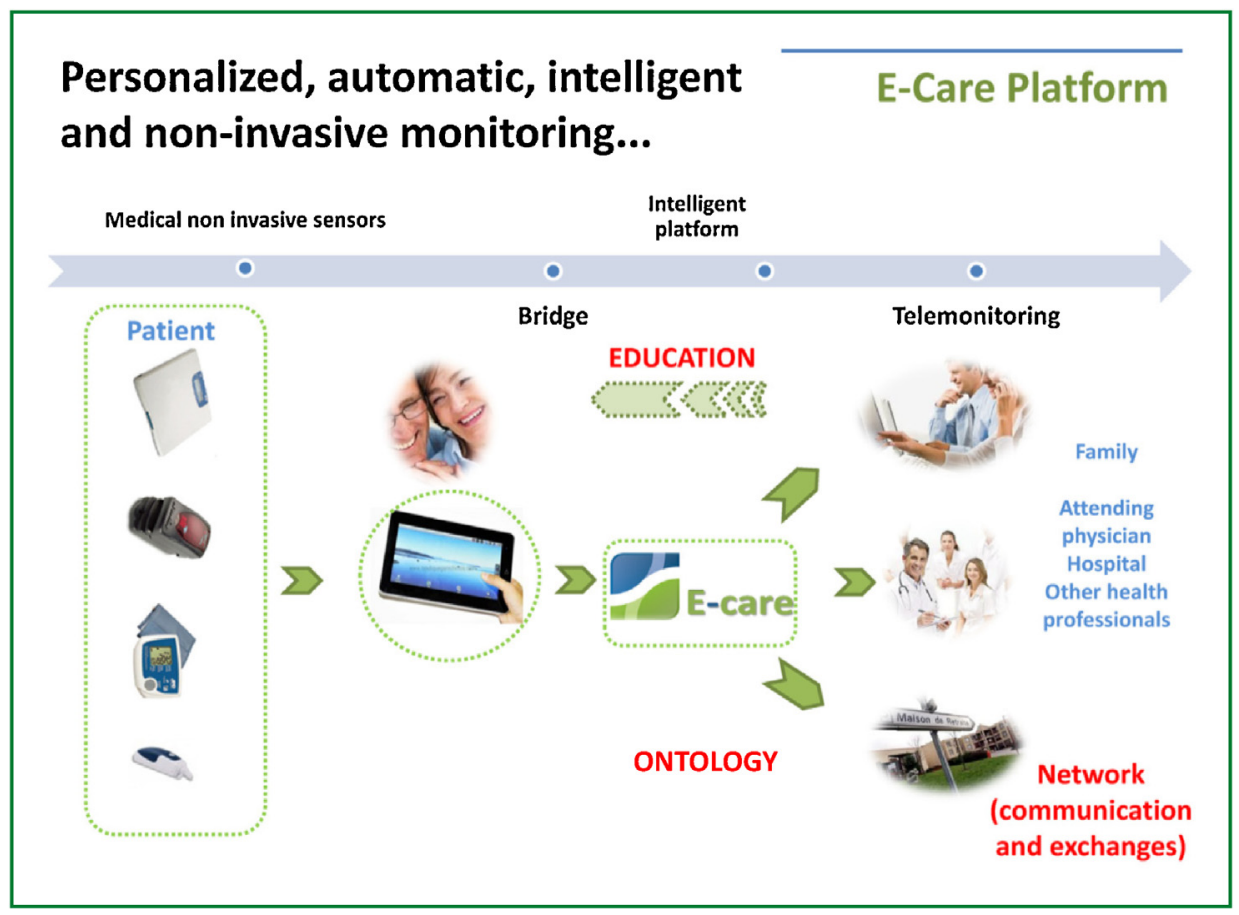

Figure 1. Version 1 of the E-care platform deployed in the Department of Internal Medicine, Diabetes and Metabolic Diseases of the University Hospital of Strasbourg (in Strasbourg, France).

Version 1 de la plateforme E-care déployée dans le Service de médecine interne, diabète et maladies métaboliques des hôpitaux universitaires de Strasbourg (à Strasbourg, en France). 
by searching for similar patterns describing critical events. This second step is effective as soon as there is a lot of data to process.

This platform also enables the sharing and management of heterogeneous data so as to integrate the necessary information required for monitoring any underlying chronic pathology, such as diabetes mellitus, renal failure, respiratory insufficiency, and so on [5-7].

\section{Patients}

The system has been deployed in a 20-bed unit of the Department of Internal Medicine, Diabetes and Metabolic Diseases of the Medical Clinic B of the Strasbourg University Hospital (in Strasbourg, France). This unit is "open" to the emergency wards and constitutes part of the HF division implemented at the Strasbourg University Hospital.

Our experimentation of the $E$-care system began in October 2013. All consecutive adult patients of the 20-bed unit were considered to be included in the study.

\section{Objectives}

The primary objective was mainly the validation of the technological and medical choices. The first phase was scheduled for 2 months' duration. In practice, the first step of the $E$ care experimentation was: to test the various functions of the system; to improve the ergonomics; to detect any vulnerability, and identify its strengths; and last to compare the results of the devices with reference devices.

In this phase, the e-platform was used in supplementation with the usual practices of health professionals.

At the time of writing, the second test phase was underway in the Department, having commenced in February 2014 (inclusion of patients still ongoing). This phase consists of the deployment of the $E$-care platform in real life, in the 20 -bed unit of our Department. Nurses use the E-care measurement devices on a daily basis when carrying out their patient rounds.

This phase relies notably on the establishment of a new human-machine interface and new inference engine. This phase includes a satisfaction and practical use survey of the system's ergonomics, filled out by caregivers and patients. The continuous gathering of data during this second phase enables us to obtain the critical mass of patients needed to conduct a more detailed analysis of the relevance of the alerts.

In the second phase, we also tested the E-care system using (pre)determined indicators, verifying the relevance of triggered alerts, in order to assess improvements that could lead to improved patient management. The goal was to detect risk situations of cardiac impairment early, before they degraded into acute HF.

\section{Administrative authorizations}

A file was submitted to the "Commission nationale de l'informatique et des libertés'" (CNIL), the French National Commission on Information Technology and Liberties. The study was presented to the local ethics committee who gave permission for the $E$-care system experimentation. The study was also registered on clinicaltrials.gov: "Anticipation and detection of heart failure with automatic treatment of information derived from non-intrusive sensors and devices"' (NCT02411279).

\section{Results \\ Characteristics of the patients}

The system has been deployed since October 2013 in a 20bed unit of the Department of Internal Medicine, Diabetes and Metabolic Diseases of the Medical Clinic B of the Strasbourg University Hospital (in Strasbourg, France) (Fig. 2). This unit is "open" to the emergency wards. Around 800 patients are hospitalized in this unit per year. To date, more than 180 patients have been included in the 2 phases of the study (inclusion of patients still ongoing).

The patient profile included in this experiment was: elderly patient, with several chronic diseases as: chronic $\mathrm{HF}>60 \%$; anemia > 40\%; arrhythmia due to atrial fibrillation $(\mathrm{AAF})>30 \%$; type 2 diabetes $>30 \%$; chronic obstructive pulmonary disease $>30 \%$; cancer $20 \%$; chronic renal failure $>15 \%$; and dementia $>15 \%$. In $25 \%$ of cases, patients present a total loss of autonomy.

\section{Results of the first phase of the experimentation}

In the first experimental phase, lasting 2 months, we validated the selected sensors deployed as part of the E-care platform using a protocol of comparative measurements from conventional hospital measuring devices (BP, heart rate, oxygen saturation, and weight) and those of the $E$-care system.

Over 150 measurements were performed by 5th- and 6th-year medical students of the Faculty of Medicine of Strasbourg during their full-time immersion internship in the Department. The retrospective analysis of these various measurements revealed a concordance between the different devices used on a daily basis in the hospital and those proposed by the E-care solution (Fig. 3).

The $E$-care system operated perfectly and the experimental phase enabled us to validate the technological choices. A qualitative survey of the students helped to positively assess the system's ergonomics. A preliminary analysis of the relevance of alerts with our first inference engine design resulted in no malfunctions.

\section{Results of the second phase of the experimentation}

At the time of writing, the second test phase was underway in the Department, having commenced in February 2014. To date, over 150 patients have been enrolled and over 1,500 measurements performed. Nurses use the $E$-care measurement devices on a daily basis when carrying out their patient rounds. This phase relies notably on the establishment of a new human-machine interface and new inference engine (Version 2 of E-care platform) (Fig. 4). This phase includes a satisfaction and practical use survey of the system's ergonomics, filled out by caregivers and patients. 

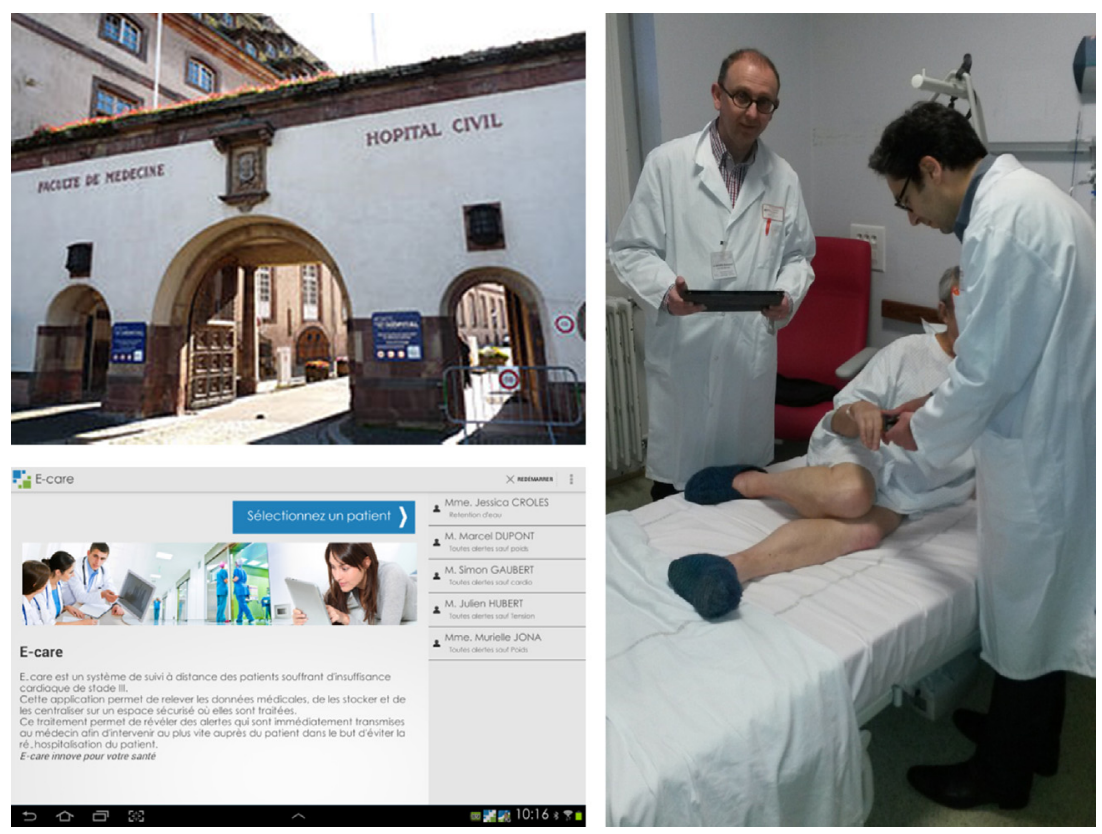

Figure 2. E-care system tested by Prof. E. Andrès and Dr. S. Talha at a patient's bedside at the Strasbourg University Hospital (in Strasbourg, France).

Système E-care testé par le Prof. E. Andrès et le Dr S. Talha au chevet d'un patient aux hôpitaux universitaires de Strasbourg (à Strasbourg, en France).

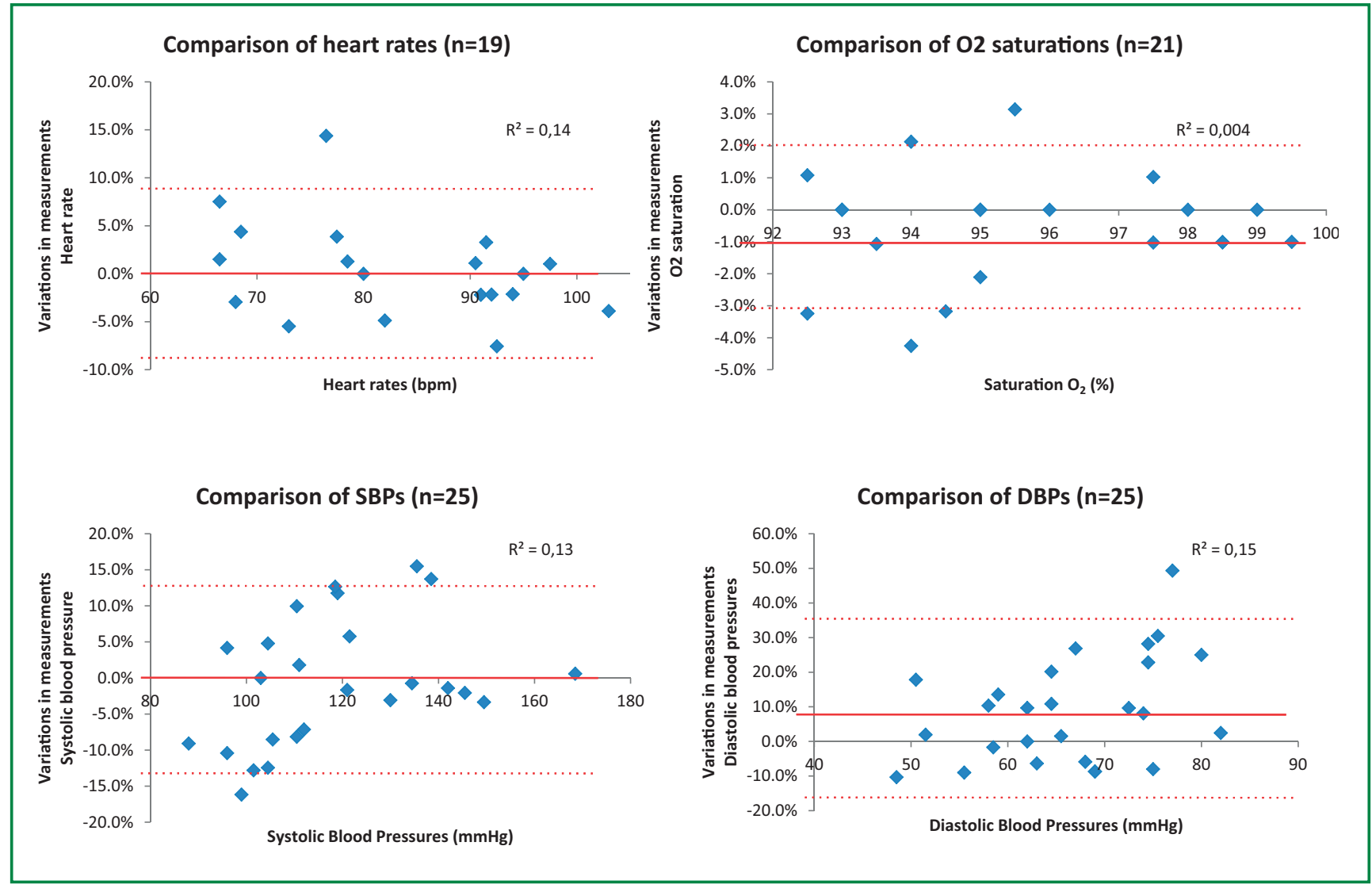

Figure 3. Comparison of measurements performed by the sensors of the E-care platform with conventional sensors used at the University Hospital of Strasbourg (Strasbourg, France).

Comparaison des mesures réalisées par les capteurs du système E-care et ceux des hôpitaux universitaires de Strasbourg (à Strasbourg, en France). 


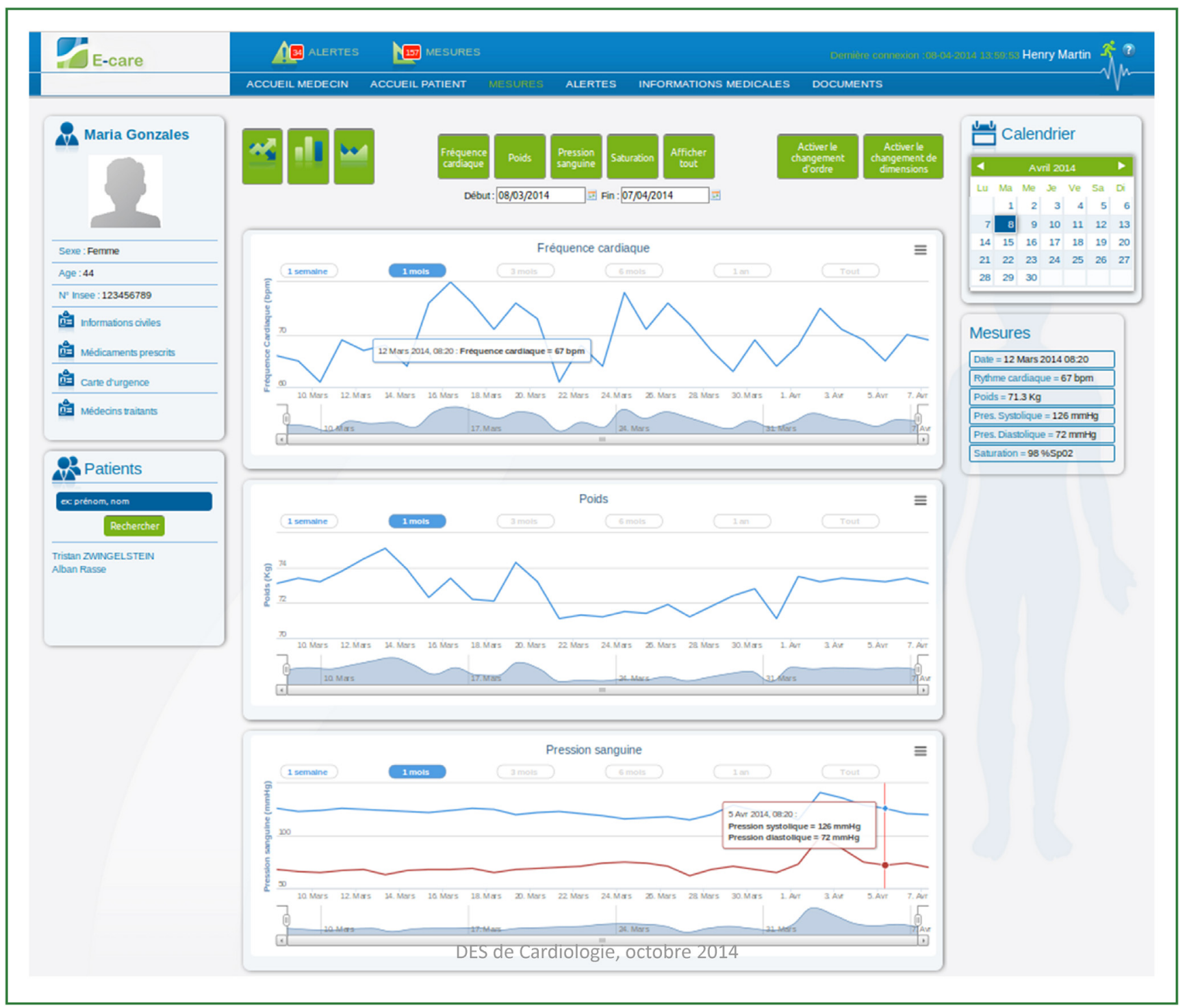

Figure 4. Man-machine interface of the system (version 2) deployed in the second phase of E-care experimentation in the University Hospital of Strasbourg (Strasbourg, France).

Interface homme-machine de la version 2 du système E-care déployé lors de la seconde phase d'expérimentation aux hôpitaux universitaires de Strasbourg (à Strasbourg, en France).

The continuous gathering of data during this second phase enables us to obtain the critical mass of patients needed to conduct a more detailed analysis of the relevance of the alerts. An analysis of the relevance of alerts shows the relevance of these alerts, admittedly on a limited number of patients with acute heart failure during hospitalization (12 patients).

\section{Discussion}

As we have demonstrated, the E-care project is developing an "intelligent" communicative platform enabling the monitoring of patients with chronic heart failure using noninvasive sensors (Fig. 1). As a result, this platform will assist health care professionals by providing an automated processing to early detect signs of cardiac impairment. Our telemonitoring $E$-Care platform uses advanced technology in order to ensure the home telemonitoring of vital signs [5-7]. The E-care platform uses an ontology designed to define a controlled vocabulary (diseases, medications, symptoms, etc.) and to model concepts related to the monitoring of HF.

The monitoring of chronic disease patients using telemedicine systems is theoretically a promising means for optimizing patient management in these cases, as already demonstrated in certain diseases, such as diabetes or chronic HF $[2,4]$. Meta-analyses have suggested that telemedicine can reduce morbidity and mortality in patients with these types of disorder [4].

Nevertheless, the results of telemonitoring studies and meta-analyses have been controversial. In reviews assessing these methods, telemedicine approaches range from computer-based support systems to ones founded on structured telephone support, or even to programs led by nurses and physicians [2,8,9]. Thereby, it is difficult to have a definitive opinion based on what we know now on whether 
or not telemedicine has a significant role to play in HF management.

Meta-analyses have suggested that telemedicine, with heath care monitoring (patients himself or health care professionals), can reduce morbidity and mortality in patients with these types of disorders. In the exhaustive metaanalysis from Anker et al., 11 studies were analyzed in the setting of a comparison between the effects of telemonitoring versus usual care (noninvasive telemedicine) [4]. Telemonitoring was found to reduce the following rates: all-cause mortality $(10.4 \%$ vs. $15.4 \%$; $P<0.0001)$; allcause hospital admission (47.2\% vs. 52.1\%; $P=0.02$ ); hospital admission related to chronic HF $(22.4 \%$ vs. $28.5 \%$; $P=0.008)$.

Still, 2 prospective clinical trials have produced results that do not support these findings $[10,11]$. The Tele-HF trial randomly assigned patients hospitalized for HF to either telemonitoring $(n=826)$ or standard care $(n=827)$ [10]. In this trial, no significant difference was noted between the telemonitoring and control groups in terms of rate of any re-admission or death from any cause within 180 days of inclusion (HR: 1.04; 95\% Cl: 0.91-1.19).

The TIM-HF trial in Germany randomly assigned stable chronic HF patients to either telemonitoring $(n=354)$ or usual care $(n=356)$ [11]. In this trial, the total mortality rate for the primary outcome of death for any cause was 8.4 per 100 patient-years of follow-up in the telemedical group, compared to 8.7 per 100 patient-years of follow-up in the usual-care group (HR: $0.97 ; 95 \% \mathrm{Cl}: 0.67-1.41 ; P=0.87$ ).

Advances in telecommunication technologies have created new opportunities to provide telemedical care as complementary treatment to the medical management of HF patients. In recent years, there has appeared to be renewed interest in France in the field of telemedicine and its applications for HF, with the development of several projects [12-15]. All these projects are non-invasive and designed to enable patient management at home or in nursing homes.

They are mostly based on standard tools for monitoring HF, namely blood pressure monitors, weighing scales, and so on, at times integrating tools enabling the feedback and transmission of collected information (Bluetooth, $3 G, 4 G$, etc.) as well as patient-healthcare professional interaction (call centers, digital tablets, websites, etc.) [12-15]. Several projects have also integrated motivational and educational tools. One of these projects ("Plateforme interactive médecins patients santé" or PIMPS - interactive platform physicians patients health) project also includes biological telemonitoring, with brain natriuretic peptide (BNP) telemonitoring [15].

These projects are based on prospective or cohort studies of HF patients, with widely varying sample sizes of 100 to 1000 patients, and different follow-up periods ranging from 3 months to 2 years, for the most part stemming from evidence-based medicine [12-15]. It is important to emphasize that the objectives or indicators of these various projects vary from modest to the more ambitious, defined as anything from improved morbidity and mortality to reduced re-admissions, enhanced quality of life, and improved health economic costs.

Compared to other telemedicine projects, the E-Care project thus envisages an "intelligent" and communicative platform to carry out home monitoring, using non-invasive sensors, of patients with chronic HF [5]. As such, this platform assists the medical team by automating the processing of information transmitted by these sensors in order to detect and report risk situations of cardiac impairment early.

To date, E-care platform is deployed in patients' homes, in the Strasbourg area, as part of the project "Insuffisance cardiaque à domicile"' (INCADO, Heart Failure at home) (grant from the Agence régionale de santé d'Alsace, the Alsace Regional Health Agency in Strasbourg, France). Several patients $(n=10)$ are included and with a daily use of the system by the personnel patient health care professionals. This project is expected to last at least 12 months before the solution can be marketed.

Once the system has been consolidated, the third phase will consist in implementing $E$-care in patients' homes, in the Strasbourg and Angers areas (in France), as well as in mid-term hospital stays, post-care, long-term care, and in retirement homes. This last phase will enable us to conduct a comprehensive study, notably in order to work on improving medical diagnosis by promoting the self-learning capacity of the system, therefore improving the detection of any anomaly at an even earlier stage.

The expected future development of this platform in providing a coherent solution in the field of medical monitoring will involve taking into account various diseases and equipment limitations. E-care is an open and scalable platform enabling the sharing and management of heterogeneous data relating to different diseases.

\section{Conclusions}

The E-care project is developing an "intelligent" communicative platform enabling the home monitoring of patients with chronic heart failure using non-invasive sensors. Our telemonitoring E-Care platform uses advanced technology and ontology process. E-care assists the health care professionals by automating the processing of information transmitted by the sensors, automatically generating alerts in order to early detect and report risk situations of $\mathrm{HF}$ impairment.

Grant: "Investissements d'avenir"' from the French government.

\section{Acknowledgements}

This work was carried out in collaboration between all authors. E. Andrès and S. Talha designed the study, wrote the protocol, and wrote the first draft of the manuscript. E. Andrès, S. Talha, A. Hajjam managed the literature searches, analyses of the results of the study. All authors read and approved the final manuscript.

\section{Disclosure of interest}

The authors declare that they have no conflicts of interest concerning this article. 


\section{References}

[1] Jessup $M$, Brozena S. Heart failure. N Engl J Med 2003;348:2007-18.

[2] Martínez-González NA, Berchtold P, Ullman K, Busato A, Egger $M$. Integrated care programmes for adults with chronic conditions: a meta-review. Int J Qual Health Care 2014;26(5):561-70, http://dx.doi.org/10.1093/intqhc/ mzu071 [Epub ahead of print].

[3] Willemse E, Adriaenssens J, Dilles T, Remmen R. Do telemonitoring projects of heart failure fit the chronic care model? Int J Integr Care 2014;14:e023.

[4] Anker SD, Koehler F, Abraham WT. Telemedicine and remote management of patients with heart failure. Lancet 2011;378:731-9.

[5] http://www.projet-e-care.fr/.

[6] Ahmed Benyahia A, Moukadem A, Dieterlen A, Hajjam A, Talha S, Andrès E. Adding ontologies based on PCG analysis in E-care project. Int J Eng Innovative Technol 2013;5: 2277-3754.

[7] Ahmed Benyahia A, Hajjam A, Andrès E, Hajjam M, Hilaire V. Including other system in E-Care telemonitoring platform. Stud Health Technol Inform 2013;190:115-7.
[8] Inglis SC, Clark RA, McAlister FA, et al. Structured telephone support or telemonitoring programmes. Cochrane Database Syst Rev 2010;(8):CD007228, http://dx.doi.org/10.1002/ 14651858.

[9] Feltner C, Jones CD, Cené CW, Zheng ZJ, Sueta CA, CokerSchwimmer EJ, et al. Transitional care interventions to prevent readmissions for persons with heart failure: a systematic review and meta-analysis. Ann Intern Med 2014;160:774-84.

[10] Chaudhry SI, Mattera JA, Curtis JP, et al. Telemonitoring in patients with heart failure. N Engl J Med 2010;363:2301-9.

[11] Koehler F, Winkler S, Schieber M, et al. Impact of remote telemedical management on mortality and hospitalizations in ambulatory patients with chronic heart failure: the telemedical interventional monitoring in heart failure study. Circulation 2011;123:1873-80.

[12] http://www.telesante-basse-normandie.fr/l-enrs-et-lesprojets/scad1642,1346.html.

[13] http://www.pimps.fr/.

[14] http://www.osicat. fr/.

[15] http://www.groupe.reunica.com/files/live/sites/reucorp/ files/VousInformer/EspacePresse/Dossiers/Dossierdepresse ReunicaDomicileDispositifdetelemedecineadomicilepour insuffisancecardiaquechronique.pdf. 